\title{
The Mentality of Crows: Convergent Evolution of Intelligence in Corvids and Apes
}

\author{
Nathan J. Emery ${ }^{1 *}$ and Nicola S. Clayton ${ }^{2}$
}

\begin{abstract}
Discussions of the evolution of intelligence have focused on monkeys and apes because of their close evolutionary relationship to humans. Other large-brained social animals, such as corvids, also understand their physical and social worlds. Here we review recent studies of tool manufacture, mental time travel, and social cognition in corvids, and suggest that complex cognition depends on a "tool kit" consisting of causal reasoning, flexibility, imagination, and prospection. Because corvids and apes share these cognitive tools, we argue that complex cognitive abilities evolved multiple times in distantly related species with vastly different brain structures in order to solve similar socioecological problems.
\end{abstract}

n Aesop's fable, a thirsty crow spied a pitcher containing a small amount of water. Unfortunately, the water was out of reach of the crow's bill, but next to the pitcher was a pile of stones. The crow began placing the stones in the pitcher, thereby raising the water until it could drink. Did the crow understand that its actions would increase the water level?

Throughout folklore, the corvids (crows, jays, ravens, and jackdaws) (Fig. 1) have been credited with intelligence. Recent experiments investigating the cognitive abilities of corvids have begun to reveal that this reputation has a factual basis. These studies have found that some corvids are not only superior in intelligence to birds of other avian species (perhaps with the exception of some parrots), but also rival many nonhuman primates. Traditionally, studies of complex cognition have focused on monkeys and apes (1). However, there is no reason to assume that complex cognition is restricted only to the primates (2). Indeed, the social intelligence hypothesis (3) states that intelligence evolved not to solve physical problems, but to process and use social information, such as who is allied with whom and who is related to whom, and to use this information for deception (4). There is evidence that some other large-brained social animals, such as cetaceans, demonstrate similar levels of intelligence as primates (5). Corvids also appear to meet many of the criteria for the use of social knowledge in their interactions with conspecifics (6).

\footnotetext{
${ }^{1}$ Sub-Department of Animal Behaviour, University of Cambridge, CB3 8AA, UK. ${ }^{2}$ Department of Experimental Psychology, University of Cambridge, CB2 3EB, UK.

*To whom correspondence should be addressed. E-mail: nje23@cam.ac.uk
}

\section{Do Corvids Have the Brains for Complex Cognition?}

The crow has a brain significantly larger than would be predicted for its body size (7), and it is relatively the same size as the chimpanzee brain. The relative size of the forebrain in corvids is significantly larger than in other birds (with the exception of some parrots) (2), particularly those areas thought to be analogous to the mammalian prefrontal cortex: the nidopallium and mesopallium (Fig. 2B) $(8,9)$. This enlargement of the "avian prefrontal cortex" may reflect an increase in primate-like intelligence in corvids $(10,11)$.

\section{An Overview of Corvid Cognitive Psychology}

To fully appreciate how corvid and ape psychology are similar, it is important to describe how corvids may represent their physical and social worlds, and how these forms of mental representation may be similar or dissimilar to those used by apes in solving similar problems. We use the term "understanding" to convey the idea that corvids social) in a way that transcends basic associative and reinforcement processes.

Tool use and manufacture. Tool use is defined as "the use of an external object as a functional extension of mouth, beak, hand, or claw, in the attainment of an immediate goal" (12). Although many birds, primates, and other animals use tools, it is not clear whether any of these species appreciate how tools work and the forces underlying their function. Perhaps the most convincing candidates are New Caledonian crows, who display extraordinary skills in making and using tools to acquire otherwise unobtainable foods. In the wild, they make two types of and apes reason about a domain (physical or tools. Hook tools are crafted from twigs by trimming and sculpting until a functional hook has been fashioned (13) and are used to poke out insect larvae from holes in trees using slow deliberate movements (14).

The crows also manufacture stepped-cut Pandanus leaves (14), which are used to probe for prey under leaf detritus, using a series of rapid back-and-forth movements or slow deliberate movements that spear the prey onto the sharpened end or the barbs of the leaf, if the prey is located in a hole. These tools are consistently made to a standardized pattern and are carried around on foraging expeditions (15). The manufacture of stepped tools appears to be lateralized at the population level (16) and tool use at the individual level $(17,18)$.

Observations of the crows' tool use in the wild suggest complex cognition. For example, there is potential cumulative evolution in the complexity of stepped tools (increasing the number of steps required to make a more complex tool), which are analogous to minor technological innovations in humans (19). There are also population differences in the types of tools manufactured (19), seemingly independent of ecological variability, which has been suggested as a form of culture in chimpanzees (20).

Laboratory experiments have confirmed the sophisticated cognitive abilities of these crows. One of them, Betty, appears to be capable of reasoning by analogy with her previous experience with hooks, by modifying nonfunctional novel material (metal wire) into hook-like shapes to retrieve food in a bucket inside a vertical tube (21). Furthermore, she chooses the correct length or diameter of tool out of a "tool box" containing tools of different lengths and widths to reach normally inaccessible food $(22,23)$.

Traveling mentally in time and space. Many corvids cache food for future consumption; either a large amount of seeds cached over a wide area, which are stored seasonally, or a smaller amount of higher-quality, perishable material, which is recovered hours or days later. These differences may require different cognitive abilities for successful retrieval. Clark's nutcrackers living at high elevations cache up to 30,000 pine seeds over a wide area and can recover them up to 


\section{R E V I E W}

6 months later (24). By contrast, western scrub jays living in more temperate environments cache fewer of a wider variety of food items that differ in their level of perishability and are recovered after much shorter periods (25).

Cache recovery may require more than simply remembering where their caches are hidden, for species that cache many types of food. These species may need to process information about the location of the cache site, the type and perishability of the cached item, and the social context of caching (26). When caching perishable food, it is prudent to learn something about the decay rates of the food, and if two or more perishable foods
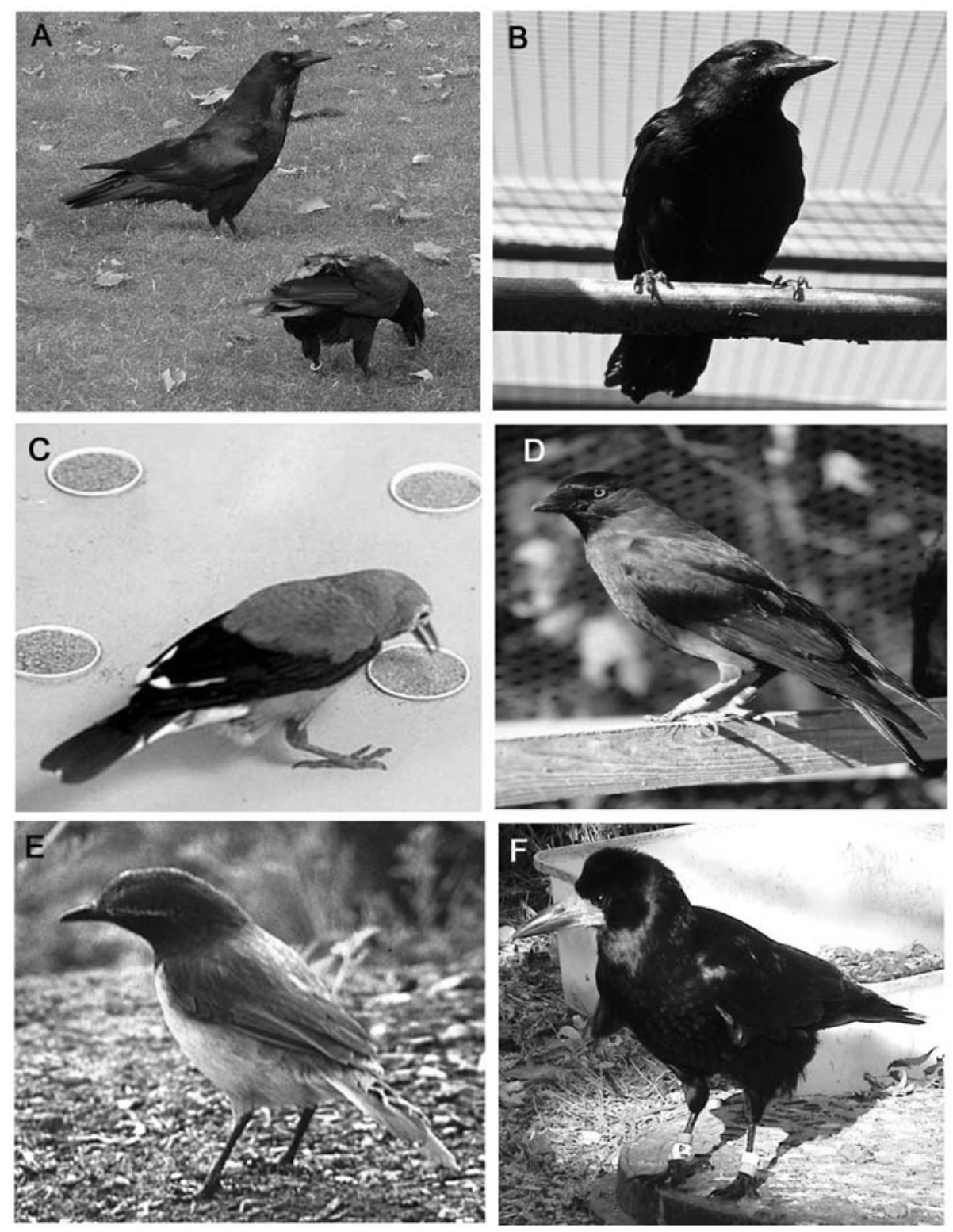

Fig. 1. Photographs of representatives of the crow-like Corvidae (ravens, crows, rooks, jackdaws, magpies, and jays) family of passerine birds. There are approximately 120 species of corvids, dispersed all over the world except in the polar regions. (A) Raven. [Photograph by N. Emery] (B) New Caledonian crow. [Photograph by A. Weir and A. Kacelnik] (C) Clark's nutcracker. [Photograph by R. Balda] (D) Jackdaw. [Photograph by A. von Bayern] (E) Western scrub jay. [Photograph by S. de Kort] (F) Rook. [Photograph by A. Seed] and selectively searched for the nonperishable caches $(27,28)$. Furthermore, they could recall when they cached different foods in the same location and could even distinguish between two caches of the same food type that had been cached at different times (29). These results suggest that scrub jays remember the "what, where, and when" of specific caching events (episodic-like memory). This representation of the time since caching is essential for the efficient recovery of perishable food items $(25,26)$.

Social cognition of cache protection and pilfering. Food storers should also be sensitive to the social context of caching, because caches are susceptible to pilfering (30). For pilferers, the ability to quickly and efficiently locate caches made by others may be the difference between successful pilfering and attack by the storer. A number of corvids observe conspecifics caching and demonstrate excellent observational spatial memory for the location of another bird's caches $(25,31,32)$.

The use of observational spatial memory as a pilfering strategy may differ between species depending on level of sociality, and as such may be an adaptive specialization (33). Do social pinyon and Mexican jays, and territorial Clark's nutcrackers, remember where another bird has cached $(31,34)$ ? Pinyon jays remembered the specific location of others' caches after 1 and 2 days, as did Mexican jays, whereas Clark's nutcrackers were only as accurate as chance after 1 day. After 2 days, the Clark's nutcrackers were only accurate at recovering their own caches, not those they had observed. (34). This finding supports the adaptive specialization of the social learning hypothesis in corvids; however, another study is more ambiguous (35). Furthermore, western scrub jays are semiterritorial, and they have highly accurate observational spatial memories (25).

The social context of caching may be viewed as an arms race between storers and pilferers, in which storers use counterstrategies to minimize the risk of having their caches pilfered (36). However, individual birds can play both roles. Storers engage in a number of cache protection strategies, which may or may not be dependent on cognitive processes. Examples of such strategies include hiding food behind barriers so that pilferers cannot see them $(37,38)$, waiting until pilferers are distracted before resuming caching $(32,39)$, leading competitors away from the location of caches (40), or making false caches that contain either an inedible item, such as a stone, or nothing at all (41). Some corvids return alone to caches they had hidden in the presence of conspecifics and readily recache them in new places unknown to the potential thief $(41,42)$.

One strategy that may decrease the probability that a pilferer will successfully 
steal another's caches is to eliminate or reduce the information available to the pilferer at the time of caching, such as caching behind a barrier (37). Of course, this behavior could be explained as "out of sight, out of mind" (that is, cache when you no longer see others present), as opposed to understanding what another can or cannot see. There is some evidence, however, that when given a choice of two cache sites that an observer can see, storers prefer to cache in the sites least visible to the observer, such as in a darkened part of a cage as compared to an illuminated part (43).

An experimental approach is crucial for understanding the processes underlying these behaviors and determining the effects of experience, particularly in relation to theory of mind. Consider the observation of birds moving food they had hidden in the presence of other individuals and recaching the items in new places when those observers were no longer present. In the wild, one might explain the presence or absence of another bird as being purely coincidental to the caching and recaching events. To test this, hand-raised western scrub jays were allowed to cache either in private or while a conspecific was watching and then recover their caches in private (42). Individuals with prior experience of pilfering another bird's caches subsequently recached food in new sites, but only when they had been observed during caching. Because the two conditions were identical at the time of recovery, the birds had to remember whether or not they had been watched during caching, and if so, whether to recache during recovery and whether in new or old sites. Note that jays without experience of themselves being pilferers did not move their caches to new sites. The inference is that these birds, who had been thieves in the past, engage in experience projection (2); that is, they relate information about their previous experience as a pilferer to the possibility of future stealing by another individual, and modify their recovery strategy appropriately. By focusing on the counterstrategies of the storer when previously observed by a potential thief, this experiment raises the possibility that recaching behavior is based on simulation of another's viewpoint (one form of mental attribution) (2). are from (9).

\section{A Cognitive Tool Kit for Corvids and Apes?}

Our review of corvid cognition suggests that these birds display similar intelligent behavior as the great apes. However, is the content of the cognitive processes based on a similar or different mental foundation? One reason why the processes may be similar is that corvids and apes face many of the same socioecological challenges, such as locating perishable food distributed in time and space or understanding the relationships between different individuals within large social groups. We suggest that these environmental problems are solved by using four cognitive tools that have driven the evolution of complex cognition in corvids and apes: causal reasoning, flexibility, imagination, and prospection (Fig. 3).

Causal reasoning. Some of the examples of tool use and manipulation described earlier suggest that some corvids, like apes, can represent the behavior of conspecifics (or heterospecifics) as caused by their intentions, beliefs, and desires; in other words, can represent that these animate beings are intentional agents. Animate beings are distinct from inanimate objects: Although they can be acted on by external forces, they also have mental states. This is an essential precursor for predicting a conspecific's or heterospecific's behavior and manipulating another for personal benefit (tactical deception). Although still controversial, corvids and apes appear to demonstrate a similar propensity for representing animate beings as causal agents $(6,45,46)$.

Flexibility. The ability to act on information flexibly is one of the cornerstones of intelligent behavior. Deployment of flexible learning strategies may form the basis for creativity as demonstrated in social and object play (47) and innovation (48). Here we
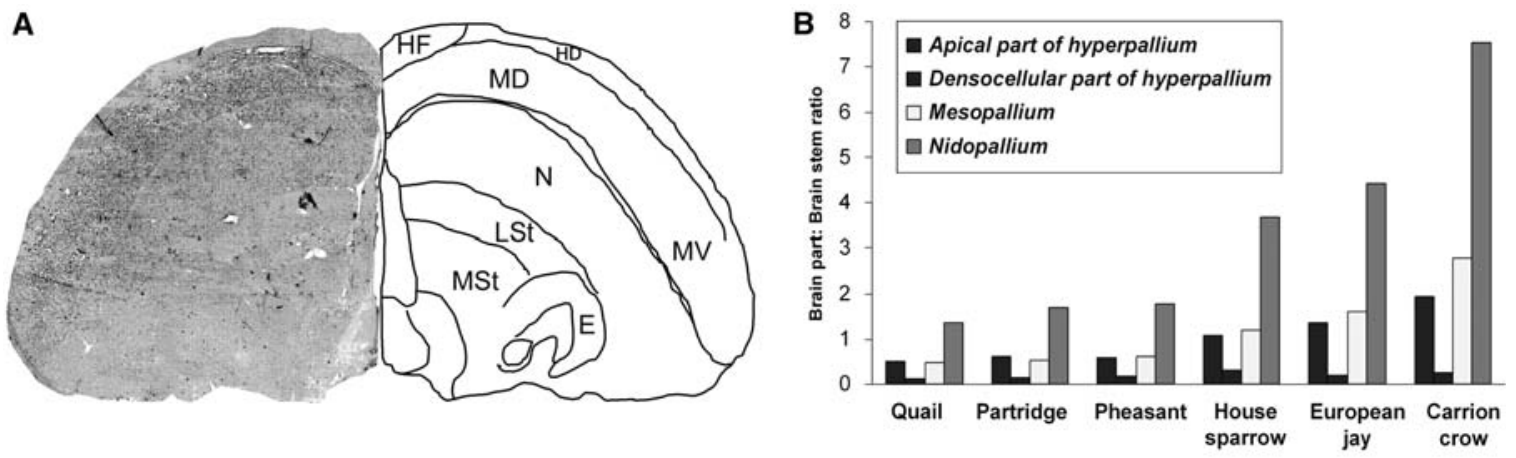

Fig. 2. (A) (Left) A low-power photograph of a coronal section through a rook telencephalon, stained with a Nissl stain. (Right) A line drawing of the corresponding half of the same section showing the location of the major parts of the telencephalon. HF, hippocampal formation; HD, densocellular part of the hyperpallium; MD, dorsal mesopallium; MV,

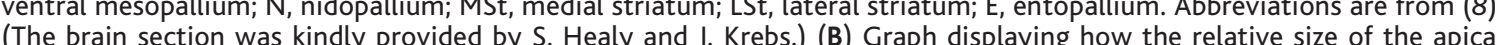
part of the hyperpallium, densocellular part of the hyperpallium, mesopallium, and nidopallium are relatively larger in passerines and particularly in the corvids (Eurasian jay and carrion crow) than in quail, partridge, and pheasant. Brain data

may understand the causal relationships by which these tools operate or are effective. In the absence of detailed knowledge about the acquisition of tool use in the wild, the role of basic instrumental conditioning processes remains unclear (44). However, what may suggest that corvid tool use transcends such noncognitive processes is Betty's innovative tool manufacture in the lab (21). The fact that she transformed a novel piece of wire into a hook-like tool suggests some appreciation of mechanical causation.

Although an understanding of physical causation suffices for interactions with inanimate objects, transactions within the social realm also require representations of mental causation. Do animals also realize that mental states (beliefs, desires, and intentions) can be causally effective? This question is best studied in the sphere of social cognition by investigating whether an animal focus on experimental evidence. In the food perishability experiments described earlier, scrub jays integrated information about the what, where, and when of a trial-unique caching event to influence their cache recovery decisions (29). However, for a bird that caches perishable food items in fluctuating temperatures (ranging from cold to extreme heat), it is critical that the bird be able to update its knowledge about decay rates and apply this knowledge to information already encoded. To investigate this, scrub jays were allowed to cache preferred, perishable crickets and less preferred, nonperishable peanuts (49). After caching, but before recovery, the jays gained new information that the crickets decayed more quickly than they had expected when they had cached them. When tested, the scrub jays used this new information and switched to recovering the peanuts rather than the now-inedible crickets. 


\section{R E V I E W}

One important aspect underlying all flexible behavior is the ability to generalize learned rules in order to apply them to novel stimuli or situations. This ability to solve transfer problems by abstracting general rules is what distinguishes rule learners from rote learners. When presented with a series of different discriminations to learn, corvids (blue jays, rooks, jackdaws, and Eurasian jays), like monkeys and apes, extract the general rule, such as win-stay, lose-shift rather than having to learn each new discrimination afresh. By contrast, pigeons appeared to be rote learners, solving the task eventually by learning each discrimination individually $(50,51)$.

Corvids also demonstrate superior abilities in other transfer problems. One case is the ability of some corvids (pinyon jays and western scrub jays) to solve transitive inference problems $(\mathrm{A}>\mathrm{B}>\mathrm{C}>\mathrm{D})$, in which the birds are trained on an ordered set of various pairwise comparisons (such as $\mathrm{A}+\mathrm{B}-, \mathrm{B}+\mathrm{C}-$, etc.). When tested, they must transfer information about the dyadic relationships to novel pairs (such as B versus
D) to solve the task. Pinyon jays outperform scrub jays on some aspects of this task (although their learning curves are similar), which has been attributed to differences in sociality (52). Indeed, pinyon jays appear to use transitive inference to rank unknown individuals in a dominance hierarchy and use this information in their subsequent social interactions (53). Finally, corvids are proficient in transferring to novel stimuli in matching and oddity discriminations. Rooks, jays, and jackdaws outperform pigeons on these problems (51). What is common to these various transfer tasks-from learning sets to transitive inference - is the ability to abstract general rules or relationships that transcend the basic learning experience. Abstraction might be an important process underlying this flexibility.

Imagination. Imagination refers to the process by which scenarios and situations that are not currently available to perception are formed in the mind's eye. One advantage of imagination is that possible situations can be practiced internally (simulated) before they are actually performed, which may be impor- tant when encountering novel stimuli within a familiar context. The ability to form representations of objects that are outside of perception (object permanence) may be a precursor of imagination. In food-caching corvids, object permanence is essential for the successful recovery of cached food; in young magpies, it develops around the same time as caching (54).

Insight, cognitive maps, and experience projection are three candidates that indicate the use of imagination. In a classic study of insight, a group of chimpanzees was presented with a problem (a banana hanging on string out of their reach), some sticks, and a series of boxes (55), which they appeared to spontaneously use to reach the banana. The implication has been that the chimpanzees imagined the solution to the problem before performing it, although this explanation has been disregarded as trial-and-error learning (44). Recent experiments in ravens may provide clearer evidence. Hand-raised ravens encountered a novel problem (meat attached to string hanging from a perch) (56). The only successful method was to pull the string up, place the foot on the

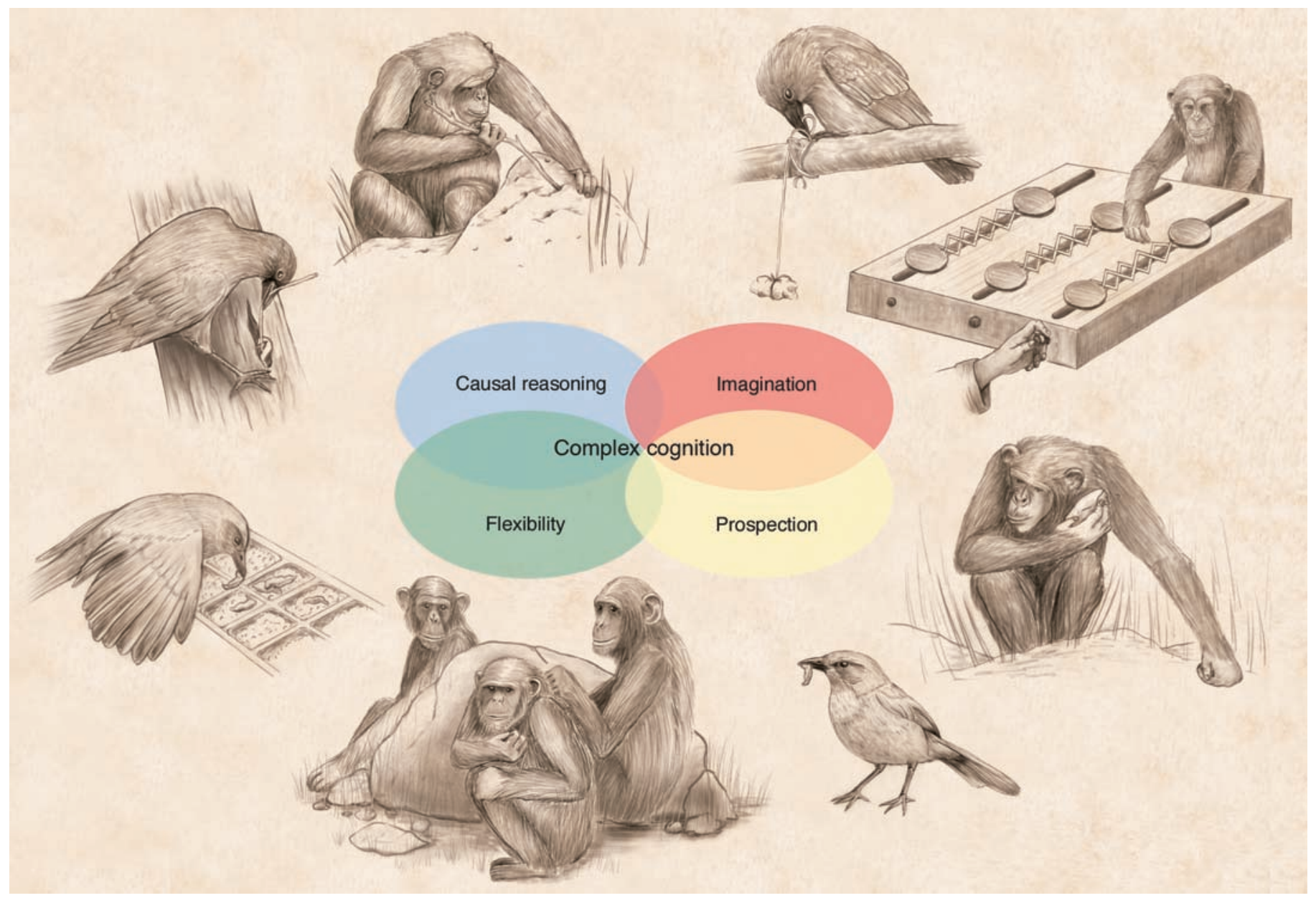

Fig. 3. Illustration of the four nonverbal cognitive tools displayed by corvids and apes, which are proposed as the basis for complex cognition: causal reasoning (New Caledonian crow and chimpanzee tool use), imagination (insight in ravens and role taking in chimpanzees), flexibility (western scrub jays' flexible memory for degraded and fresh food items and tactical deception in apes), and prospection (western scrub jays recaching food and chimpanzees carrying stone tools). These cognitive tools interact in different ways to produce complex cognition. [Drawing by C. Cain] 
string after each pull up, and repeat this multiple times until the food was in reach, a solution some ravens reached on the first trial (that is, without recourse to trial-and-error learning). Furthermore, the ravens chose the correct string from a number of alternatives, choosing the string attached to the food, as opposed to a similarly sized stone. They did not fly off with the attached food, nor did they attempt to pull up items that were too heavy.

A second candidate for imagination is the use of a cognitive map (a mental representation of the major landmarks in the environment) to aid in navigation, particularly when novel routes are required. Although the issue of whether animals possess cognitive maps remains controversial (57), the enhanced spatial memory of the food-caching corvids might be a prime candidate for indicating their existence. It has been suggested that Clark's nutcrackers may use something akin to a cognitive map to locate a hidden goal object, even when the position of the fixed distal landmarks changed with respect to the local landmarks and the goal (58).

A final candidate for imagination is experience projection or role taking, in which an individual simulates another's experiences and perspective (2). This ability implies that an observer forms a representation of a model's perspective or experiences that are similar to or different from their own. In a cooperative task to investigate role taking, chimpanzees, but not rhesus monkeys, reversed the roles they were trained on $(59,60)$, suggesting that the chimpanzees may have taken their partner's perspective; however, both monkeys and chimpanzees failed to immediately transfer to the opposite role on the first trial (61).

The example of recaching demonstrated by western scrub jays may present a case for imagination, because the jays needed to have remembered the relevant previous social context, used their own experience of having been a thief to predict the behavior of a pilferer, and determined the safest course of action to protect the caches from pilferage (42).

Prospection. In the previous discussion of imagination, an agent could simulate scenarios with respect to past events; however, one function of simulation may be to imagine possible future events, so-called prospection. Although various behaviors have been proposed as examples of future thinking, it is important to distinguish between those behaviors that are tuned to current thinking and motivational states and those that are tuned to future thinking and motivational states $(62,63)$. Caching would appear to provide a natural example of future planning. Food is hidden in the present to provide sustenance for the future. However, if caching is controled by hunger, then this current motivational state may facilitate caching without any appreciation of becoming hungry in the future (63).

The example of recaching by scrub jays may also provide the best evidence for prospection (42). Recaching items in new sites when an observer saw the placement of caches, but not when the caches were made in private, suggests that the jays were using a strategy to protect their caches from future cache pilfering, not because of hunger levels. It is important to stress that prospection is highly reliant on retrospection (63).

\section{Conclusions}

There are many aspects of corvid and ape cognition that appear to use the same cognitive tool kit: causal reasoning, flexibility, imagination, and prospection. We suggest that nonverbal complex cognition may be constructed through a combination of these tools. Although corvids and apes may share these cognitive tools, this convergent evolution of cognition has not been built on a convergent evolution of brains. Although the ape neocortex and corvid nidopallium are both significantly enlarged, their structures are very different, with the ape neocortex having a laminar arrangement and the avian pallium having a nuclear arrangement (2). It is unclear what implications these structural differences have. However, cognition in corvids and apes must have evolved through a process of divergent brain evolution with convergent mental evolution. This conclusion has important implications for understanding the evolution of intelligence, given that it can evolve in the absence of a prefrontal cortex.

\section{References and Notes}

1. M. Tomasello, J. Call, Primate Cognition (Oxford Univ. Press, New York, 1997).

2. N. J. Emery, N. S. Clayton, in Comparative Vertebrate Cognition: Are Primates Superior to Non-Primates? L. J. Rogers, G. Kaplan, Eds. (Kluwer Academic, New York, 2004), pp. 3-55.

3. N. K. Humphrey, in Growing Points in Ethology, P. P. G Bateson, R. A. Hinde, Eds. (Cambridge Univ. Press, Cambridge, 1976), pp. 303-317.

4. R. W. Byrne, A. Whiten, Machiavellian Intelligence: Social Evolution in Monkeys, Apes and Humans (Clarendon Press, Oxford, 1988).

5. L. Marino, Brain Behav. Evol. 59, 21 (2002).

6. N. J. Emery, in Comparative Analysis of Mind, S. Watanabe, Ed. (Keio Univ. Press, Tokyo, 2004), pp. 181-213.

7. H. J. Jerison, Evolution of the Brain and Intelligence (Academic Press, New York, 1973).

8. A. Reiner et al., J. Comp. Neurol. 473, 377 (2004).

9. G. Rehkamper, H. D. Frahm, Z. Zilles, Brain Behav. Evol. 37, 125 (1991).

10. L. Lefebvre, N. Nicolakakis, D. Boire, Behaviour 139 939 (2002).

11. L. Lefebvre, P. Whittle, E. Lascaris, A. Finkelstein, Anim. Behav. 53, 549 (1997).

12. J. van Lawick-Goodall, Adv. Study Behav. 3, 195 (1970).

13. G. R. Hunt, R. D. Gray, Proc. R. Soc. London Ser. B 271, 88 (2004).

14. G. R. Hunt, Nature 379, 249 (1996).

15. G. R. Hunt, Proc. R. Soc. London Ser. B. 267, 403 (2000)

16. G. R. Hunt, R. D. Gray, M. C. Corballis, Nature 414, 707 (2001).

17. R. Rutledge, G. R. Hunt, Anim. Behav. 67, 327 (2004)

18. A. A. S. Weir, B. Kenward, J. Chappell, A. Kacelnik, Proc R. Soc. London Ser B Biol. Lett. 271, 344 (2004).
19. G. R. Hunt, R. D. Gray, Proc. R. Soc. London Ser. B 270, 867 (2003).

20. A. Whiten et al., Nature 399, 682 (1999).

21. A. A. S. Weir, J. Chappell, A. Kacelnik, Science 297 981 (2002).

22. J. Chappell, A. Kacelnik, Anim. Cognit. 5, 71 (2002).

23. J. Chappell, A. Kacelnik, Anim. Cognit. 7, 121 (2004)

24. R. P. Balda, A. C. Kamil, Anim. Behav. 44, 761 (1992).

25. N. S. Clayton, D. P. Griffiths, N. J. Emery, A. Dickinson, Philos. Trans. R. Soc. London Ser. B 356, 1483 (2001).

26. S. R. de Kort, S. Tebbich, J. M. Dally, N. J. Emery, N. S. Clayton, in Comparative Cognition, T. R. Zentall, E. Wasserman, Eds. (Oxford Univ. Press, New York, in press).

27. N. S. Clayton, A. Dickinson, Nature 395, 272 (1998).

28. N. S. Clayton, A. Dickinson, J. Comp. Psychol. 113, 403 (1999).

29. N. S. Clayton, K. Yu, A. Dickinson, J. Exp. Psychol. Anim. Behav. Process. 27, 17 (2001).

30. S. B. Vander Wall, Food Hoarding in Animals (Univ. of Chicago Press, Chicago, 1990).

31. P. A. Bednekoff, R. P. Balda, Behaviour 133, 807 (1996)

32. B. Heinrich, J. W. Pepper, Anim. Behav. 56, 1083 (1998)

33. R. P. Balda, A. C. Kamil, P. A. Bednekoff, in Current Ornithology, V. Nolan, E. D. Ketterson, Eds. (Plenum, New York, 1996), vol. 13, pp. 33-66.

34. P. A. Bednekoff, R. P. Balda, Anim. Behav. 52, 833 (1996)

35. J. J. Templeton, A. C. Kamil, R. P. Balda, J. Comp. Psychol. 113, 450 (1999).

36. N. J. Emery, J. M. Dally, N. S. Clayton, Anim. Cognit. 7, 37 (2004).

37. J. M. Dally, N. J. Emery, N. S. Clayton, Anim. Behav., in press.

38. T. Bugnyar, K. Kotrschal, Anim. Behav. 64, 185 (2002).

39. H. Kallander, Anser Suppl. 3, 124 (1978).

40. T. Bugnyar, K. Kotrschal, Anim. Cognit. 7, 69 (2004).

41. B. Heinrich, Mind of the Raven (Harper Collins, New York, 1999).

42. N. J. Emery, N. S. Clayton, Nature 414, 443 (2001).

43. J. M. Dally, N. J. Emery, N. S. Clayton, Proc. R. Soc. London Ser. B Biol. Lett., in press.

44. D. J. Povinelli, Folk Physics for Apes (Oxford Univ. Press, New York, 2000).

45. B. Hare, J. Call, B. Agnetta, M. Tomasello, Anim. Behav. 59, 771 (2000).

46. B. Hare, J. Call, M. Tomasello, Anim. Behav. 61, 139 (2001).

47. J. Diamond, A. B. Bond, Behaviour 140, 1091 (2003)

48. S. M. Reader, K. N. Laland, in Animal Innovation, S. M. Reader, K. N. Laland, Eds. (Oxford Univ. Press, Oxford, 2003), pp. 3-35.

49. N. S. Clayton, K. S. Yu, A. Dickinson, J. Exp. Psychol. Anim. Behav. Process. 29, 14 (2003).

50. M. W. Hunter, A. C. Kamil, Psychon. Sci. 22, 271 (1971)

51. B. Wilson, N. J. Mackintosh, R. A. Boakes, Q. J. Exp. Psychol. B 37, 313 (1985).

52. A. B. Bond, A. C. Kamil, R. P. Balda, Anim. Behav. 65 479 (2003).

53. G. Pas-y-Mino, C. A. B. Bond, A. C. Kamil, R. P. Balda, Nature 430, 778 (2004).

54. B. Pollok, H. Prior, O. Gunturkun, J. Comp. Psychol. 114, 148 (2000).

55. W. Kohler, The Mentality of Apes (Vontage Books, New York, ed. 2, 1927).

56. B. Heinrich, Auk 112, 994 (1995)

57. A. D. Bennett, J. Exp. Biol. 199, 219 (1996).

58. B. M. Gibson, A. C. Kamil, J. Comp. Psychol. 115, 403 (2001).

59. D. J. Povinelli, J. E. Nelson, S. T. Boysen, Anim. Behav. 43, 633 (1992).

60. D. J. Povinelli, K. A. Parks, M. A. Novak, Anim. Behav. 44, 269 (1991).

61. C. M. Heyes, Behav. Brain Sci. 21, 101 (1998).

62. T. Suddendorf, M. C. Corballis, Genet. Soc. Gen. Psychol. Monogr. 123, 133 (1997).

63. N. S. Clayton, T. J. Bussey, A. Dickinson, Nat. Rev. Neurosci. 4, 685 (2003).

64. N.J.E. is supported by a Royal Society Research Fellowship. The writing of this review was supported by grants from the Biotechnology and Biological Sciences Research Council (grants S16565 and BBS/B/05354), the Royal Society, and the University of Cambridge. We thank A. Dickinson, S. de Kort, C. Rutte, G. Hunt, and A. Kacelnik for comments on the manuscript.

10.1126/science. 1098410 